\title{
ТЕНДЕНЦИИ РАЗВИТИЯ РЫНКА ТЕЛЕКОММУНИКАЦИОННЫХ УСЛУГ
}

\author{
СЕрлыгина Е. Г., ORCID: 0000-0003-2049-3845; канд. экон. наук \\ Владимирский государственный университет им. А.Г. и Н.Г. Столетовых, \\ 2. Владимир, Россия, erlygina@mail.ru \\ (СФилимонова В. Д., Владимирский государственный университет им. А.Г. и Н.Г. \\ Столетовых, г. Владимир, Россия, filimonova.viktory@gmail.com

\section{TRENDS IN THE DEVELOPMENT OF THE TELECOMMUNICATION SERVICES MARKET}

\author{
CErlygina E., ORCID: 0000-0003-2049-3845; Ph.D., Vladimir State University, \\ Vladimir, Russia, erlygina@mail.ru
}

CFilimonovaV., Vladimir State University,Vladimir, Russia, filimonova.viktory@gmail.com

Аннотация. Рассмотрены тенденции развития рынка телекоммуникационных услуг. Предложены инновационные подходы в системах связи, способствующие дальнейшему развитию телекоммуникационных услуг. Новые инновационные решения и новые услуги позволят повысить конкурентоспособность, расширить рынок, сократить отставание от зарубежных компаний.

Abstract. The development trends of the telecommunications services market are considered. Innovative approaches in communication systems are proposed to promote the further development of telecommunications. New innovative solutions and new services will improve competitiveness, expand the market, reduce the backlog of foreign companies.

Ключевые слова: телекоммуникационные услуги, инновационные подходы, повышение конкурентоспособности.

Keywords: telecommunication services, innovative approaches, increase of competitiveness.

\section{Введение}

Рынок телекоммуникационных услуг стремительно развивается, увеличивается рост числа инфо-телекоммуникационных отраслей экономики. Что в условиях всемирной глобализации является фактором, обеспечивающим экономический рост страны. Существует несколько тенденций развития мирового рынка телекоммуникаций [1].

Во-первых, наблюдается либерализация в отрасли. Это значит, что государственный контроль за регулируемостью ценовой политики операторов связи ушел на второй план. Позволяя компаниям свободно конкурировать между собой. Таким образом, оператором ничего не остается, кроме как предлагать выгодные тарифные пакеты.

Во-вторых, консолидирование компаний. Конкуренция в итоге приводит к тому, что некоторые компании не справляются с течением рынка, что ведет к слиянию и поглощению в телекоммуникационной отрасли. Объединение дает возможность снижать долгосрочные средние издержки, перенимать имеющийся опыт, технологии для увеличения доли рынка.

В-третьих, изменение технологий позволяет применение облачного хранения, обработки и передачи информации, объединяя сервера, программное обеспечение, а также 
каналы связи. Работа с облачными хранилищами позволяет снижать расходы и повышать эффективность предприятия. Особенность от традиционного способа работы с информацией, «облако» не привязано к конкретным аппаратным платформам или территории. Клиент имеет возможность доступа в любой точке мира с помощью устройства с интернет-соединением. Это позволяет оперативно реагировать на переменчивость бизнес-задач и потребностей рынка [2].

\section{Материал и методы исследования}

Из-за быстрых течений в информационно-технологической сфере, в отрасли существует потребность постоянного пересмотра и видоизменения портфелей предоставляемых услуг. Именно за счет регулярных обновлений можно создать гибкую тарифную политику. Это вызвано постоянно увеличивающимся числом абонентов, которым необходим доступ к сети. Услуги сотовой связи настолько устойчивое положение заняли на рынке, что люди стали отказываться от фиксированной связи [1]. На Рисунке 1 представлена динамика роста числа абонентов сотовой связи и интернета в мире.

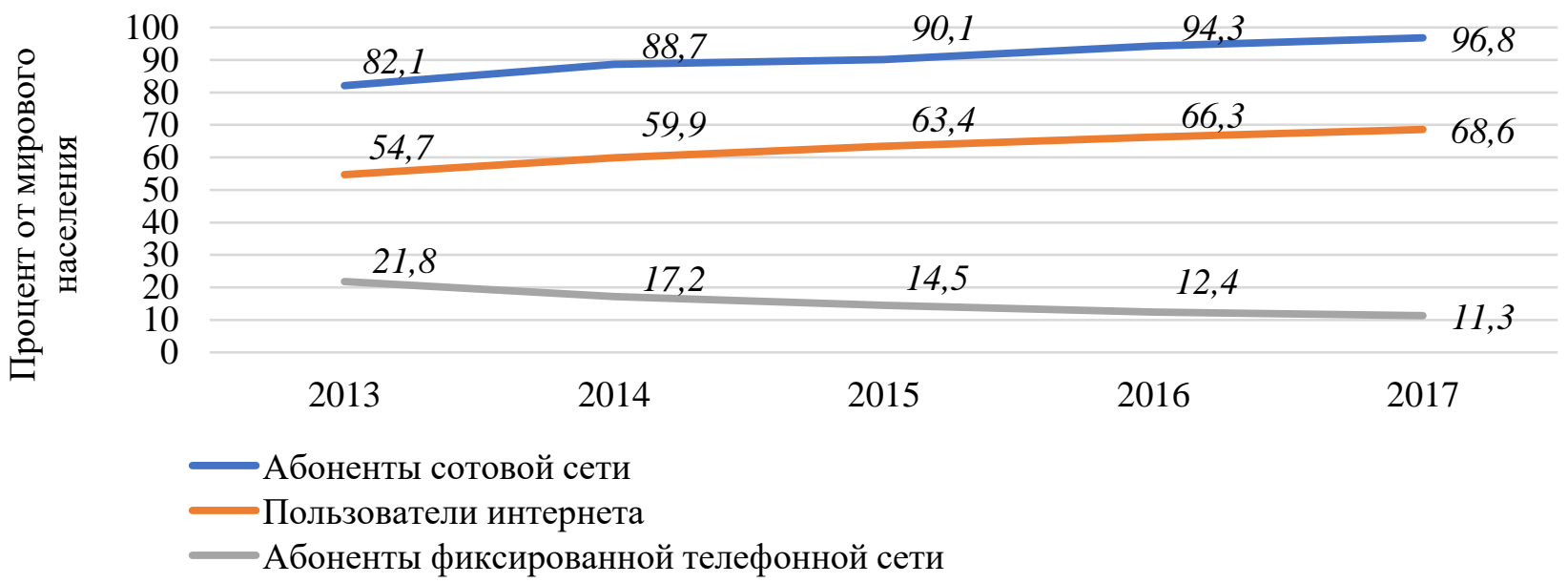

Рисунок 1. Динамика количества абонентов сотовой связи, фиксированной сети и сети интернет (https://marketing.rbc.ru/articles/10081/).

В настоящее время по всему миру насчитывается около 3,5 млрд пользователей сети интернет, из которых 2 млрд проживают в стабильно развивающихся странах. Без сотовой сети не могут обойтись 96,8\% населения, что говорит о действительно обширном рынке данного вида услуг.

В России аудитория интернет пользователей среди молодых людей от 16 до 29 лет составляет 99\%, возрастная группа пользователей от 30 до 54 лет составляет 88\%, от 55 лет - 36\% (Рисунок 2) [2].

Эксперты считают, что мировой рынок телекоммуникаций на данный момент достиг своей зрелости, а, следовательно, не будет демонстрировать в ближайшее время высоких темпов роста. На Рисунке 3 показана динамика отечественного рынка телекоммуникаций.

C учетом аспектов международной практики и тенденций развития, российским компаниям удается осваивать территории международной отрасли. Но несмотря на это, отечественному рынку по-прежнему не хватает технических мощностей, что мешает преодолеть инфраструктурное отставание и формирование полноценно конкурентоспособного рынка. Также, небольшой прирост, обуславливается, в основном отказом операторами от безлимитных тарифов и ценовой конкуренции. 


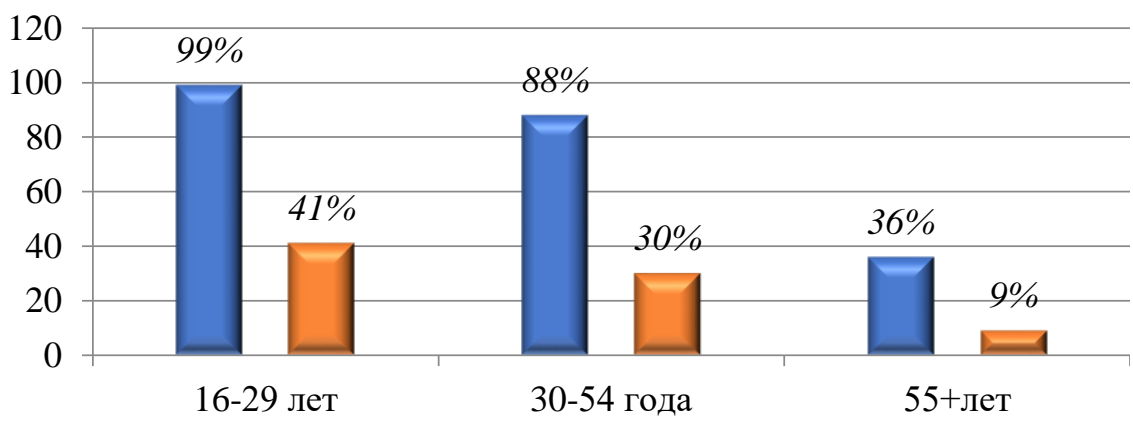

囯Пользуются интернетом

目Пользуются мобильным интернетом

Рисунок 2. Возрастной профиль пользователей интернета в России, 2018 (https://marketing.rbc.ru/articles/10081/).

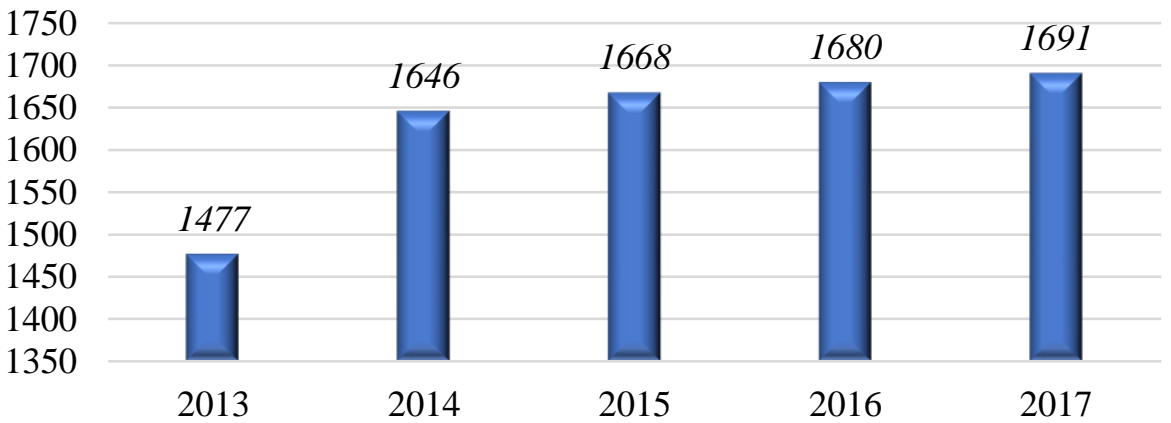

Рисунок 3. Динамика темпов роста российского телекоммуникационного рынка (https://marketing.rbc.ru/articles/10081/).

Сегментами отрасли на данный момент являются: сотовая и фиксированная связь, интернет, услуги широкополосного доступа, цифровое телевиденье, спутниковые информационные системы.

Клиентами телекоммуникационных услуг являются как физические, так и юридические лица, в том числе некоторые другие операторы, использующие, например, вышки сотовой связи. Все эти услуги можно разделить на три группы (Таблица 1).

\section{ТЕЛЕКОММУНИКАЦИОННЫЕ УСЛУГИ}

Таблица 1.

\begin{tabular}{ll}
\hline \multicolumn{1}{c}{ Группь } & \multicolumn{1}{c}{ Услуги } \\
\hline Услуги для корпоративных & -видеоконференции \\
клиентов & -корпоративная телефонная сеть \\
& -приватные виртуальные сети VPN \\
& -аренда специальных каналов связи \\
Услуги для сторонних & -аренда цифровой магистрали \\
операторов & -услуги центра обработки данных \\
& -пропуск всех видов трафика (голосовой, сигнальный, интернет) \\
Услуги для физических лиц & -домашний интернет \\
& -домашний телефон \\
& -мобильная связь \\
& -цифровое телевиденье \\
\hline
\end{tabular}


Сегодня лидирующие позиции на рынке телекоммуникационных услуг связи занимают такие компании как МТС (Рисунок 3), его доля рынка (по объему выручки на российском рынке на 2016 г.) составила 27,3\%, Мегафон - 21,2\%, Ростелеком - 20,3\%, ВымпелКом (бренд Билайн) - 18,6\%, доля рынка Теле2 составила 7,2\% [1].

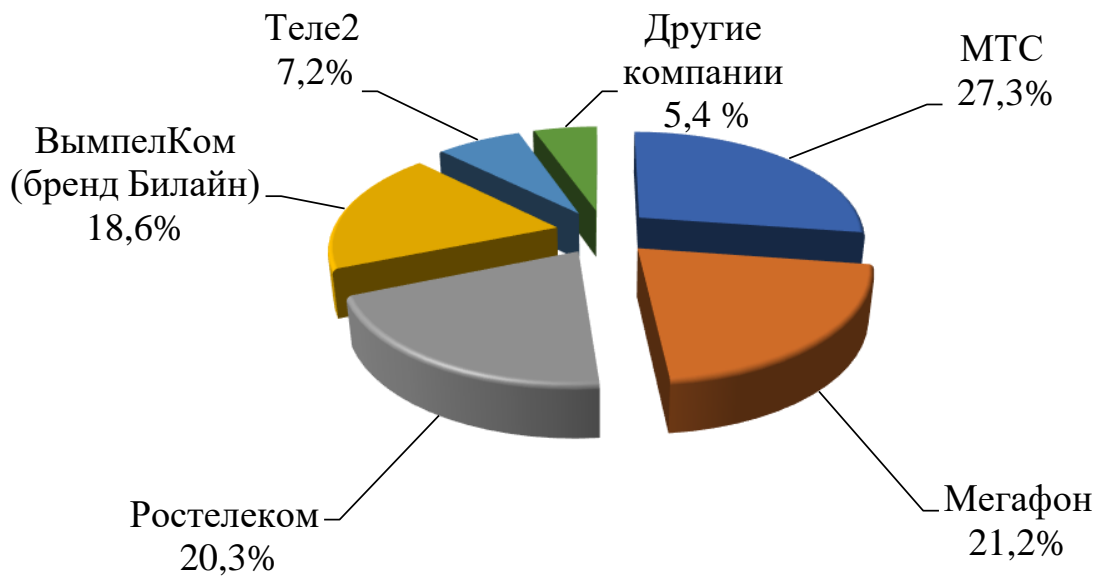

Рисунок 4. Доля крупнейших компаний рынка Телекоммуникационных услуг (https://marketing.rbc.ru/articles/10081/).

\section{Результаты и обсуждение}

Традиционно программы лояльности сохраняют и привлекают своих клиентов за счет разного рода вознаграждений, как правило в виде скидок на совершение будущих покупок. По мере трансформации направленности рынка на использование современных технологий, разнообразные организации могут получать все больше ценных данных о своих потребителях, чем когда-либо прежде [3].

Сегодня операторы телекоммуникационных услуг сталкиваются с постоянно возрастающей конкуренцией. Применение различных маркетинговых инструментов для привлечения клиентов не приносит желаемого результата. Использование инновационного подхода в системах связи необходимо для дальнейшего развития телекоммуникационной отрасли России [4]. Необходимы новые инновационные решения и новые услуги. Одними из таких решений могут стать: внедрение системы Bigdata, усовершенствование IT-cepвисменеджмента. Live-чат, внедрение новой услуги «Умный дом».

Основные характеристики предложенных услуг представлены в Таблице 2.

\section{ТЕЛЕКОММУНИКАЦИОННЫЕ РЕШЕНИЯ}

Таблица 2.

\begin{tabular}{|c|c|}
\hline Услуги & Описание \\
\hline Bigdata & $\begin{array}{l}\text { Большие корпоративные данные позволяют организации собирать, обобщать и } \\
\text { анализировать большие объемы информации о клиентах с использованием } \\
\text { различных источников. Компания может использовать информацию для } \\
\text { понимания предпочтений каждого клиента. }\end{array}$ \\
\hline Онлайн-чаты & $\begin{array}{l}\text { Обмен сообщениями с оператором. Пользователи интернета и смартфонов } \\
\text { предпочитают это способ связи с компанией, так как считают его наиболее } \\
\text { комфортным, особенно в случаях негативного опыта или впечатления о продукте } \\
\text { или услуге, в сравнении с телефонным или личным разговором с сотрудником. }\end{array}$ \\
\hline «Умный дом» & $\begin{array}{l}\text { Новая услуга на мировом рынке, продукт для обеспечения комфорта и } \\
\text { безопасности жилья. Система может контролировать освещение, климат, } \\
\text { развлекательные системы и некоторые подключенные приборы. }\end{array}$ \\
\hline
\end{tabular}


Ключевыми преимуществами системы Big Data выделяются:

-Получение качественно новых знаний о потребителе, за счет комплексного анализа в едином аналитическом хранилище;

- Расширение функциональности существующих информационных систем;

- Повышение эффективности при работе с клиентами;

-Решения, построенные по технологии Big Data, предоставляют коммерческим организациям эффективный инструмент для планирования бизнеса на основе достоверной информации о поведении клиентов и изменении рыночных тенденций.

Онлайн-чаты широко распространены в клиентском обслуживании в сфере оптовых и розничных продаж, однако в последнее время, организации начали постепенно внедрять такую функцию и в техническую поддержку.

Одним из приоритетов компании является время ее клиентов. При использовании онлайн-консультантов организация может не только сохранить драгоценное время, но и бюджет, затрачиваемый на содержание колл-центра, так как один оператор может обрабатывать одновременно сразу несколько чатов.

Для клиентов, которые предпочитают «живое» общение необходимо предусмотреть бесплатный звонок через приложение, который является альтернативным телефонному звонку. Возможность выбрать один из нескольких вариантов благотворно сказывается на потребительской лояльности.

С подключением услуги «Умный дом» потребитель может настроить систему под свои нужды и требования, прописать сценарии управления, а также назначить удаленный доступ через мобильное приложение на любом из своих мобильных устройств или устройств членов семьи. Домашняя автоматизация подключает подконтрольные устройства к центральному шлюзу, за счет которого и происходит дистанционное управление.

\section{Заключение}

Телекоммуникационная отрасль остается одной из самых динамично развивающихся отраслей с очень высоким уровнем конкуренции. В борьбе за клиента компании приходится ориентироваться на прогноз изменений в выборе покупателей, поиск новых возможностей для удовлетворения рыночного спроса, повышения качества оказываемых услуг. Новые инновационные решения и новые услуги позволят операторам связи повысить конкурентоспособность, расширить рынок, сократить отставание от зарубежных компаний.

\section{Список литературы:}

1. Каримов М. К. Услуги в сфере телекоммуникации и их продвижение // Молодой ученый. 2015. №13. С. 35-37.

2. Вартанян А. А. Особенности инновационного подхода в сфере телекоммуникаций. Открытое образование. 2011. №2. С. 120-124.

3. Striy L., Orlov V., Zakharchenko L. Economic Activity of Enterprises of the Telecommunication Industry in Conditions of Implementation of the Newest Technologies // Baltic Journal of Economic Studies. 2019. V. 5. №1. P. 207-213. DOI: 10.30525/2256-0742/2019-5-1-207213.

4. Ashmarina, S. I., Kandrashina, E. A., \& Dorozhko, J. A. (2019). Digitalization as a Source of Transformation of Value Chains of Telecommunication Companies Using the Example of PAO Megaphone // Digital Transformation of the Economy: Challenges, Trends and New Opportunities. 2019. P. 581-589. DOI: 10.1007/978-3-030-11367-4_57. 


\section{References:}

1. Karimov, M. K. (2015). Services in the field of telecommunications and their promotions. Molodoi uchenei, (13), 35-37.

2. Vartanyan, A. A. (2011). Features of innovative approach in the field of telecommunications. Otkrytoe obrazovanie, (2), 120-124.

3. Striy, L., Orlov, V., \& Zakharchenko, L. (2019). Economic Activity of Enterprises of the Telecommunication Industry in Conditions of Implementation of The Newest Technologies. Baltic Journal of Economic Studies, 5(1), 207-213. doi.org/10.30525/2256-0742/2019-5-1-207-213.

4. Ashmarina, S. I., Kandrashina, E. A., \& Dorozhko, J. A. (2019). Digitalization as a Source of Transformation of Value Chains of Telecommunication Companies Using the Example of PAO Megaphone. In: Digital Transformation of the Economy: Challenges, Trends and New Opportunities, 581-589. doi:10.1007/978-3-030-11367-4_57.

Работа поступила в редакцию 17.04.2019 2.
Принята к публикаиии 22.04.2019 2.

Ссылка для циитирования:

Ерлыгина Е. Г., Филимонова В. Д. Тенденции развития рынка телекоммуникационных услуг // Бюллетень науки и практики. 2019. Т. 5. №5. С. 285-290. https://doi.org/10.33619/24142948/42/37.

Cite as (APA):

Erlygina, E., \& Filimonova, V. (2019). Trends in the Development of the Telecommunication Services Market. Bulletin of Science and Practice, 5(5), 285-290. https://doi.org/10.33619/24142948/42/37. (in Russian). 